\title{
Database Design of three Dimensional Simulation and Optimization System for Mine Ventilation Network
}

\author{
SHEN Yun \\ Faculty of Mechanical and Electronic Engineering \\ Jiangxi University of Science and Technology \\ Ganzhou, China \\ Shenyun75@126.com
}

\begin{abstract}
According to the characteristic of three dimensional simulation system for mine ventilation and database technology situation, the systems database was built by SQL Server. This paper analysed the data model, data dictionary, database access control strategy and technology, which provided solid dependence for the stable operation of the simulation system.
\end{abstract}

Keywords-database design; data model;SQL Server; mine ventilation

\section{INTRODUCTION}

The mine ventilation simulation and optimization system was integrated with ventilation network graphic rendering, wind net calculating, wind network parameter annotationm. It could directly show the mine ventilation network actual appearance and ventilation state. So that it could provide effective methods for mine managers to understand underground ventilation conditions, and could provide technical basis for mine ventilation system control. This system was programmed by visual basic under C/S structure, whose database was established and managed by SQL Server. And the database was accessed by ODBC. The mine ventilation network was simulated by SolidWorks software. The crystal report software was used to output all data reports. All part was organic integrated to realize the simulation and optimization. The whole structure is showed as figure1.

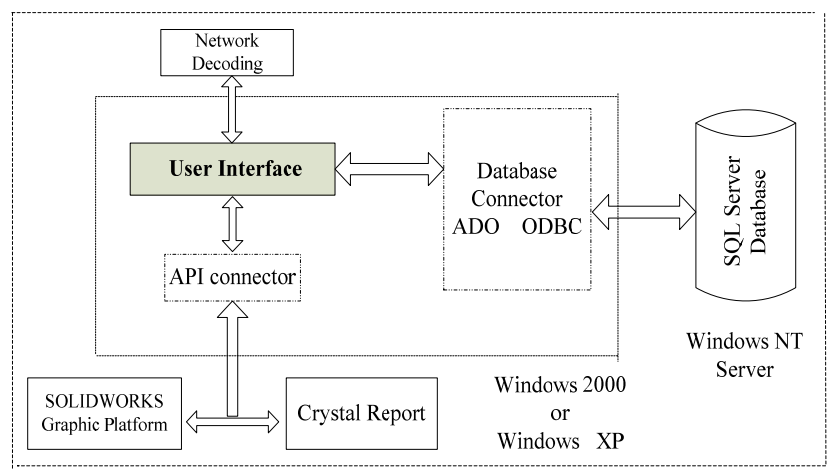

Figure 1. structure figure of simulation and optimization system for mine ventilation network

Identify applicable sponsor/s here. If no sponsors, delete this text box. (sponsors)

\section{SYSTEM DATABASE CONSTRUCTION}

\section{A. System data model}

According to the system function, system database mainly includes two parts data. One is the network simulation data, such as node data, roadway data,ventilation structure data, working plane data, the simulation graphics file data. The second is the wind net calculating data, such as the wind road parameters, fan parameters, natural wind pressure parameters, scheme parameters, the calculating results, the diagnosis parameters. The two parts data are relative independence, but have immanent connection. Finally, there are some basic data for system operation, such as personnel authority, etc.The E-R model of system data is shown as figure2.

\section{B. Ssystem data dictionary}

Data types: roadway data, the wind road data, basic data. The system data dictionary was established. the partial contents was listed follow:

- $\quad$ Node parameter table:Node parameter table stores basic position parameters of ventilation network system, including: node number, $\mathrm{X}$ coordinate value, $\mathrm{Y}$ coordinate value, $\mathrm{Z}$ coordinate value, ventilation scheme identifier. The node number and ventilation scheme identifier are integer, and $\mathrm{X}, \mathrm{Y}, \mathrm{Z}$ coordinate values are single precision floating-point data. Don't permit to have two same node number in the same ventilation scheme. Do not permit to have two nodes with the same $\mathrm{X}, \mathrm{Y}, \mathrm{Z}$ coordinate values in the same ventilation scheme yet. And all fields couldn't be empty.

- Branch roadway parameter table:Branch roadway parameter table stores following fields: branch roadway name, branch roadway number, initial node number, terminal node number, ventilation scheme identifier. All fields are integer and couldn't be empty except branch roadway name. Branch roadway name is string and could be empty. Do not permit to have two branch roadways with the same number in the same ventilation scheme. Do not permit to have two branch roadways both with the same initial number and terminal node number in the 
same ventilation scheme yet. But there could be branch roadway with the same name.

- Ventilation circuit characteristic parameter table: Ventilation circuit characteristic parameter table stores following fields: wind road number, initial node number, terminal node number, parallel branch number, fan position, fan number, wind resistance, local wind resistance of downcast entrance, local wind resistance of fan inlet, natural wind pressure, initial air volume, whether fixed air volume, ventilation scheme identifier. Some fields are integer data, the others are single precision floating-point data.

- Fan curve characteristic parameter table: Fan curve characteristic parameter table stores following fields: fan number, points (the condition number for fan curve simulation), fan code, fan air volume (the air quantity flowing through fan in unit time $\left(\mathrm{m}^{3} / \mathrm{s}\right)$, it has multiple parameters, just as points, has commonly 7), fan air pressure (when the air flowing through fan, total energy of per cubic meter air supplyed by the fan, so-called total pressure of the air blower, which is formed by static pressure and dynamic pressure. it also has multiple parameters, just as points, has commonly 7), ventilation scheme identifier.

- Ventilation network calculating setting parameter table: Ventilation network calculating setting parameter table stores following fields: wind network hole number, node numbers, fan numbers, edge number of wind resistance in unit length multiplied by wind road length, maximum iterative number for a node air volume balance calculation, maximum iterative number for a mesh pressure balance calculation, air volume calculation accuracy being hoped, ventilation scheme identifier.

- Calculating results parameter table 1: Calculating results parameter table 1 stores following fields: wind road number, entrance number, export number, wind road friction wind resistance, entrance local wind resistance, export local wind resistance, wind road air volume, inlet air volume, export air volume, wind road friction resistance, entrance local friction resistance, export local friction resistance, wind road total resistance, whether there is a fan, fan curve number, ventilation scheme identifier, etc.

- Calculating results parameter table 2 (some scheme parameter): Calculating results parameter table 2 stores following fields: wind network hole number, node numbers, fan numbers, edge number of wind resistance in unit length multiplied by wind road length, maximum iterative number for a node air volume balance calculation, maximum iterative number for a mesh pressure balance calculation, air volume calculation accuracy being hoped, ventilation scheme identifier.
- Ventilation scheme parameter table: Ventilation scheme parameter table stores three fields: scheme identifier, scheme name, scheme state. Among them: scheme identifier is integer, which is coded automatically with $1,2, \ldots$ by the ventilation simulation system. Scheme name and scheme state are string.

In addition, the system database have graphic library setting parameter table, system users management parameter table (used for system database and system safety management), and some excessive tables.

\section{DATABASE ACCESS TECHNOLOGY}

\section{A. Database access control strategy}

Database access control is power control for users to access all sorts of resources in database. The user access control by SQL Server is divided into two stages: One is security account authentication, the other is access permission authentication. In the security account authentication stage, windows operating system or SQL Server authenticates user's login. If the authentication succeeds, the user could connect the SQL Server, otherwise database server will refuse to the user's connection request. Access permission confirmation is that, after the user successfully connected to the SQL Server, the system judge whether the user account have the database access permission according to user account storded in the database which is corresponding to server login identification.

(1) authentication model of SQL Server security account

The server security authentication of SQL Server has the following two models: Windows authentication model and the authentication model mixed by Windows and SQL Server. Windows authentication is more safe, because Windows operating system has higher security (C2 level safety standards). SQL Server authentication management is relatively simple. When SQL Server runns on Windows NT or Windows 2000, the system administrator must develop authentication model of systems use. When mixed authentication model being used, SQL Server is allowed to use not only Windows authentication model but also SQL Server authentication model. This system server is using the mixed authentication model.

After completion of the SQL Server installation, SQL Server will set up a special account named sa, who is the abbreviation of system manager. The sa account has the highest management authority and can perform all operations within the scope of the server. Neither could sa user name be changed, nor could sa be deleted. But sa's password could be changed. Just after finishing the installation of SQL Server, sa account has no any password, so sa should be set password as soon as possible.

(2) access permission confirmation

After realizing the user security login, check the user's next safety rank is the database access authority. Database access authority achieves through mapping the relationship between database users and login account. Security account authentication decides whether the user could send command 
to server, while access permission confirmation decides whether the user could execute T - SQL language in the database[2].

\section{B. Database access control technology $O D B C$}

Open Database Connectivity — ODBC is a database access standard defined by Microsoft. By ODBC application program could not only access database in the local computer, but also could access database on heterogeneous platform, such as SQL Server, Oracle, Informix or DB2, etc.

ODBC realizes database access through a set of standard functions (ODBC API), which is based on standard SQL language. In order to access database server by the ODBC , database server must support SQL language. Programmers could easily development client/server application program based on ODBC without understanding these ODBC API. Because in many popular programming languages, such as Visual Basic, Power Builder, Visual $\mathrm{C}++$, etc. code layer which packages all kinds of standard functions of ODBC are provided. Developers could directly use these standard functions. This system used ODBC interface model and has set up a system ODBC data source so-called "jcexp".

\section{CONCLUSION}

- Based on analysising overall structure of mine ventilation simulation and optimization system, the system data model is determined.

- The system database was established through SQL Server, the mine ventilation simulation and optimization system was developed by VB.
- The seamless connection between interface and database was realized by ODBC, the user could access and maintain the database through interface.

\section{REFERENCES}

[1] NI Jing-feng, LIU Jian. Database design of simulation of mine ventilation system[J]. Journal of Liaoning Technical University, 2004.5(23): 585-587

[2] XIE Zhi-yu, ZHENG Lin-hua, WANG Zi-bin. Design and Application of SQL Server[J]. Computer Knowledge and Technology(Academic Exchange), 2006.32: 30-31

[3] LI Bo, ZUO Wei, LIN Wei-guo. Several Kinds of Practical Approaches that Sql Server Database Resume[J]. Journal of Communication University of China(Science and Technology), 2006.1(13): 53-56

[4] ZHANG Li, WANG Qiang, DONG Li. Tutorial of SQL Server Database Principles and Application[M]. Beijing: Tsinghua university press, 2003.1

[5] ZHANG Li, WANG Qiang, DONG Li. Tutorial of SQL Server Database Principles and Application[M]. Beijing: Tsinghua university press, 2003,1

[6] ZHAO Li-hua, GAO Hong-bo, LI Guo-cai. A Research About Visible Graph-Database Of Mine Ventilation System.SHANXI Coal, 2004,(24)4:13-15

[7] ZHAO Jian-hua. Database Platform Design of Mine Ventilation Resistance Measurement Network [J].Modern Mining,2009(483)7:110-111

[8] LI Gang. Graphics Data Management Technology Applied to Mine Ventilation CAD[J]. Coal Science and Technology, 2010,(38)1:81-84

[9] WANG Xiang-rui, HUANG Guo-hua. A Technique of Accessing Database by Using ADO[J]. Journal Of CHANGCHUN University, 2010,(20)2:62-63

[10] XU Yun-dong, SHEN Yun. Design and Management of Database of the Engineering Drawing Information System[J]. Manufacturing Informtion Engineering Of China,2009,(38)7:15-18

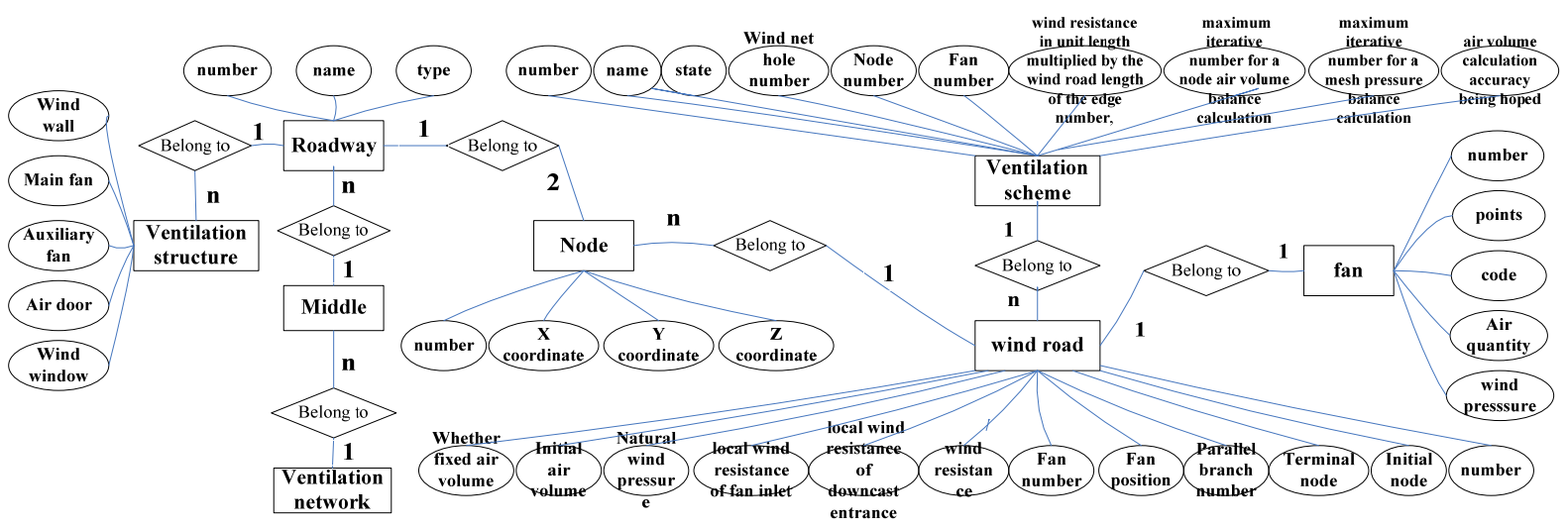

Figure 2. E-R model figure of system data 